\title{
Mgus or Multiple Myeloma - The Importens of the Right Diagnosis
}

\author{
Eirik Tjønnfjord Rikshospitalet ${ }^{* 1}$, Bruno Bengtsson $^{2}$ and Claudia Irene Stahlberg ${ }^{3}$ \\ ${ }^{1}$ Oslo University Hospital, Norway \\ ${ }^{2}$ Department of hematology, Esbjerg Hospital, SVS, Denmark \\ ${ }^{3}$ Department of pathology, Odense University Hospital, Denmark
}

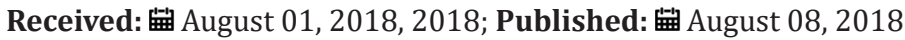

*Corresponding author: Eirik Tjønnfjord, department of hematology, Oslo University Hospital, Rikshospitalet, Norway

Abbreviations: MGUS: Monoclonal Gammapathi of Undetermined Diagnosis; MM: Multiple Myeloma; BM: Bonemarrow; HD: High Dose; SCT: Stem Cell Transplantation; GP: General Practioner; LKC: Leukocytes; TRC: Trombocytes; Hb: Hemoglobin; MGUS: Monoclonal Gammopathi of Undetermined Signifiscans.

\section{Introduction}

Monoclonal Gammapathi is cause by the expansion of a monoclonal plasma cell, that gives rise to a monoclonal immunoglobulin. Monoclonal Gammapathi of Undetermined Diagnosis (MGUS) is the reason for approximately $50 \%$ of all cases of a plasma M-component. MGUS is a non-malignant condition, with a prevalence of $3-4 \%$ in the general population over 50 years. Approximately 1-2\% of the patient's progress into Multiple Myeloma (MM), Macroglobulinemia or Lymphoma per year, and after 15-20 years ca $25 \%$ of the patients have developed a malignant disease. MGUS is therefore often looked at as a pre-malignant state, and every patient diagnosed with MM has started as MGUS (Landgren et al 2009, Weiss et al 2009). MGUS is distinguished from MM by the amount of plasma cells in the bone marrow (BM) (in general under $10 \%$, though depending on the immunoglobulin) or the presence of MDE-criterion. There might be Bence-Jones proteinuria and/or suppression of immunoglobulins in both cases.

MGUS-patients do not have any symptoms of their condition and is usually diagnosed after a M-component is found coincidental blood sample. There are no known risk factors for developing MGUS, and the reason for progression to MM has not yet been found. MM is diagnosed in ca 300 patient a year in Denmark. It is a malignant BM-disease evolving from the plasma cells [1]. MM is a "uncurable" disease, but the prognosis has improved over the last couple of decades, and the prevalence is therefore increasing. The improved prognosis is based on the introduction of high dose (HD) chemotherapy followed by autologous stemcelltransplantation (SCT) in the 90's and later new drugs as Thalidomide, Bortezomib, Lenalidomide etc. The supporting therapy has also improved and contributes to the better outcome. The prognosis for MM in
Denmark is not precisely known, but the Danish Myelomatosis Database will during the coming years contribute with more knowledge on this matter. The most common clinical symptoms of MM are osteolytic bonelesions, hypercalcimia, anemia, nefropathi and increased tendency of infections.

\section{Case}

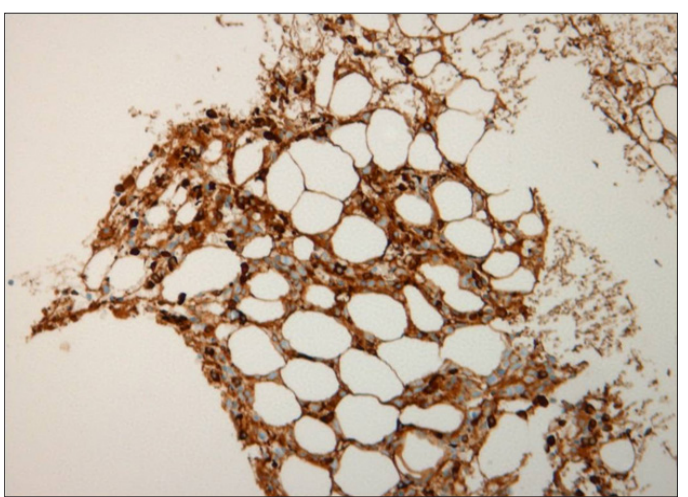

Figure 1A: Hypoplastic Bone Marrow, coloured for kappa+ plasmacells (CD138). At admittion.

A 53-year old male was admitted to the hospital confused and under suspicion for a medicine-overdose of Methotraxat. He also had fever and possible pneumonia, and a mild epistaxis. He was known having a severe asthma, and an alcohol problem. 2 years prior he was started on Methotraxat for his asthma, but he never came to his controls, and was therefore overdrawn to his general practioner (GP). He never saw his GP and had taken Methotraxat 
for 2 years without being controlled, neither by blood samples nor physical check-up [2]. At admittion we found CRP (C-reactive protein) 120, Leukocytes (LKC) 12, Thrombocytes (TRC) 200 and Hemoglobin $(\mathrm{Hb})$ 8,7. The rest of his paraclinic was normal. He was started on Tazocin iv and Fluconazol because of oral candidiasis.4 days later he did not get better. CRP 259, LKC 0,68, TRC 17 and Hb 6,9 (pancytopenia). He is being transfused with thrombocytes, changed in antibiotics to Meropenem iv and is also started on Neupogen to help rising the leukocytes. It does not help and an acute bonemarrow (BM) examination is performed, and an ultrasound of the abdomen is also executed. At admittion and again before changing his antibiotics he is vinylated and his Urine is checked for bacteria, both negative (Figures 1A \& 1B), [3].

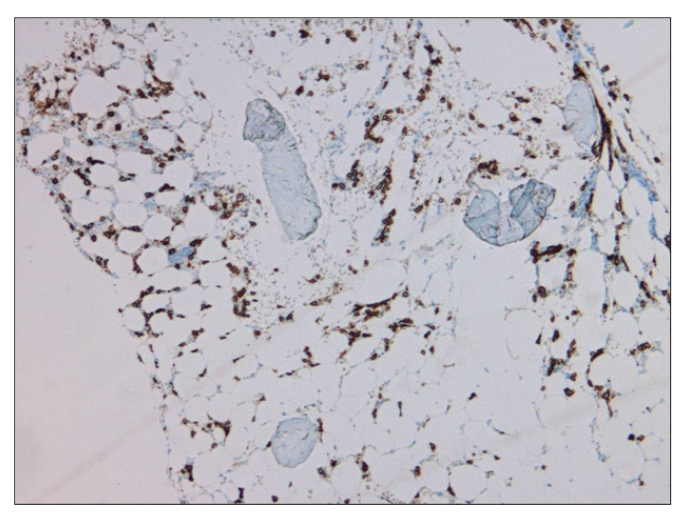

Figure 1B: Normoplastic BM, coluored for kappa+ plasmacells. After regeneration.

The BM shows $60 \%$ monoclonal IgA plasma cells, prognostic for Multiple Myeloma (MM), and the blood follows up with elevated IgA and suppressed IgG and IgM, normal Beta-2- microglobulin, Ca-ion and creatinin. X-ray of the bones is without osteolytical changes. The patient is gradually becoming better, his fever drops, and his CRP decreases as well as his hematological parameters. 2 weeks later his $\mathrm{Hb}$, TRC and LKC is normalized and before starting the treatment for his MM, the BM is controlled. Surprisingly the monoclonal plasma cells only accounts for approximal 5\% and the diagnosis is changed to Monoclonal Gammopathy of Undetermined Significands (MGUS), and no treatment is indicated [4].

\section{Discussion}

MGUS is a benign condition and those not need treatment, while $\mathrm{MM}$ is a malign progressive disease where the controls must be closer and often will need treatment shortly after diagnoses, either some kind of anti-neoplastic treatment or supportive care, f.ex. transfusion, Bisphosfonat etc. The correct diagnosis is therefore extremely important, as far as prognosis but also because of the treatment that not is "free" but has side effects and in some cases can be hard for the patients. In this case the MM was diagnosed on "false" conditions, because the BM was performed when the patient was pancytopen, and therefore the marrow did not give us the full picture. The malignant plasma cells had a survival benefit and made up an abnormal percentage of the cells. After regeneration the diagnose was altered, something that makes an enormous difference for the patient and his prognosis (Table 1).

Table 1: Blood samples during admittens to hospital. At admittens pancytopenia and infection due to an overdose of Metothraxat. Finally, at discharge peripheral hematology is normal and the diagnosis of MGUS is given.

\begin{tabular}{|c|c|c|c|c|c|}
\hline & $\mathbf{1 2 / 7 - 1 3}$ & $\mathbf{1 5 / 7 - 1 3}$ & $\begin{array}{c}\mathbf{1 7 / 7 -} \\
\mathbf{1 3}\end{array}$ & $\mathbf{2 3 / 7 - 1 3}$ & $\begin{array}{c}\mathbf{2 6 / 7 -} \\
\mathbf{1 3}\end{array}$ \\
\hline $\mathrm{Hb}(\mathrm{mmol} / \mathrm{L})$ & 6,9 & 7,0 & 6,3 & 7,1 & 7,2 \\
\hline LKC (10E9/L) & 0,68 & 0,69 & 0,79 & 18,6 & 14,8 \\
\hline TRC (10E9/L) & 62 & 17 & 27 & 202 & 476 \\
\hline LDH (U/L) & & & 136 & 429 & 289 \\
\hline CRP (mg/L) & 261 & 166 & 163 & 12 & 4,6 \\
\hline IgA (g/L) & & & 13,5 & 12,9 & 11,9 \\
\hline IgG (g/L) & & & 4,3 & 4,9 & 4,4 \\
\hline IgM (g/L) & & & 0,19 & 0,25 & 0,26 \\
\hline $\begin{array}{c}\text { Kappa/Lambda } \\
\text { ratio }\end{array}$ & & 4,6 & 3,1 & \\
\hline $\begin{array}{c}\text { Kappa (frit) } \\
\text { (mg/L) }\end{array}$ & & 33,3 & 19,3 & \\
\hline $\begin{array}{c}\text { Lambda (frit) } \\
\text { (mg/L) }\end{array}$ & & 7,3 & 6,3 & \\
\hline
\end{tabular}

Even though MGUS is a non-malignant condition, research has shown that patients diagnosed with MGUS is at increased risk of developing several different pathological conditions and malignancies, including DVT/PE, fractures, hypocalcemia and more, indicating that there is an increased osteoclastic activity and hyper coagulating tendency early in the pathogenesis of plasma cell neoplasia. There has also been shown that patients with MGUS has an impaired life expectancy, even if they do not progress to MM or Lymphoma.

\section{References}

1. (2003) The International Myeloma Working Group, Criteria for the classification of monoclonal gammopathies, multiple myeloma and related disorders: a report of the International Myeloma Working Group. British Journal of Haematology 121: 749-757

2. (2012) Diagnostik og behandling af myelomatose. Retningslinje fra Dansk Myelomatose Studie Gruppe (DMSG), Germany.

3. Kyle RA, Therneau TM, Rajkumar V, Offord JR, Larson DR, et al. (2002) A long-term study of prognosis in monoclonal gammopathy of undetermined significance. N Engl J Med 346: 564-569.

4. Landgren (2010) Monoclonal Gammopathy of Undetermined Significance and Smoldering Myeloma: NewInsights into Pathophysiology and Epidemiology. Hematology pp. s295-310. 
ISSN: 2574-1241

DOI: 10.26717/BJSTR.2018.07.001544

Eirik Tjønnfjord. Biomed J Sci \& Tech Res

(C) (i) This work is licensed under Creative

Submission Link: https://biomedres.us/submit-manuscript.php

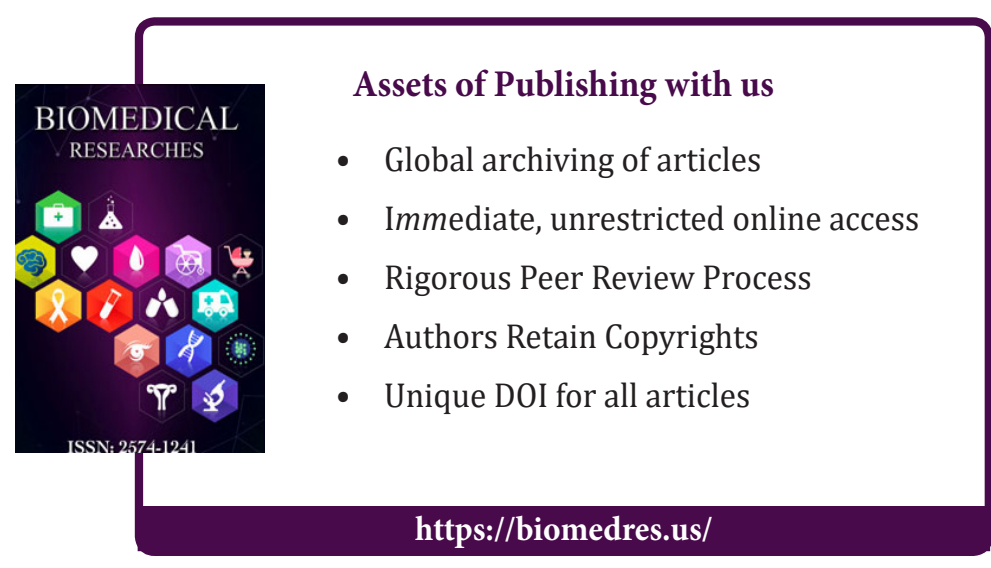

